\title{
SIGHTSEEING
}

\section{Paisagens arquivadas}

Isabela Umbuzeiro Valent ${ }^{1}$

Civilização da imagem? Na verdade uma civilização do clichê, na qual todos os poderes têm interesse em nos encobrir as imagens, não forçosamente em nos encobrir a mesma coisa, mas em encobrir alguma coisa na imagem. (Deleuze, 1990, p.32) ${ }^{2}$
* Terapeuta ocupacional e fotógrafa. Mestranda em Artes (Museu de Arte Contemporâna da Universidade de São Paulo), onde pesquisa relações entre os dispositivos fotográficos e audiovisuais e processos de subjetivação. Desenvolve oficinas audiovisuais e fotográficas em projetos sociais, de cultura e de saúde. Rua Vespasiano, 1243, Vila Romana. São Paulo, SP, Brasil. 05.044-050. isabelavalent@usp.br

As imagens deste número de Interface são fragmentos de um ensaio fotográfico ${ }^{3}$ em realização. As fotografias que compõem esse número foram realizadas entre 2010-2012, em locais considerados turísticos em Paris, Berlim e Rio de Janeiro. São os chamados "sightseeing". A expressão, de origem inglesa, costuma não ser traduzida em outras línguas e é repetida constantemente em guias de viagem e revistas de turismo. Enquanto os turistas, dotados com suas respectivas câmeras, iphones, ipads etc., trabalham intensamente na produção de suas imagens, minha câmera se volta para outros ângulos, produzindo um olhar à espreita. Vistas de elementos do dispositivo fotográfico no contemporâneo.

Ao contrário do que imaginava, quase não sou notada pelos turistas ao fotografá-los. Sob o ponto de vista da minha objetiva, a paisagem viva dos seres em trânsito, vindos de toda a parte do planeta, empenhados na fabricação de suas imagens, se movimenta rapidamente. Paisagens que talvez não apareçam nas telas ali presentes. Em poucos minutos, chegam, fotografam e se vão. Curioso o esforço empreendido pelos seres em percorrer o globo, gesto que supõe o encontro com o outro, o estrangeiro, o estranho, quando os gestos e as formas de habitar os espaços parecem apenas se repetir em diferentes cenários.

\author{
2 DELEUZE, G. [1990]. A \\ imagem-tempo. Trad. \\ Eloisa de Araújo Ribeiro. \\ São Paulo: Brasiliense, \\ 2005. \\ ${ }^{3}$ A edição das imagens \\ apresentadas nesse \\ número contou com a \\ colaboração da fotógrafa \\ Val Lima.
}


CRIAÇÃO

sightseeing

sightseeing

visita a lugares turísticos

excursão

turismo

sight

visão/olhar/vista

ponto de vista

vislumbre/visão vaga

aspecto/espetáculo

avistar/mirar

a vista, no ato

aparência estranha/bizarra/ridícula

seeing

olhar/vista

considerado

observador

verificar

entender

acompanhar

paisagens arquivadas 


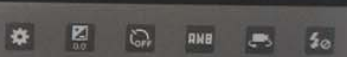

[I] 



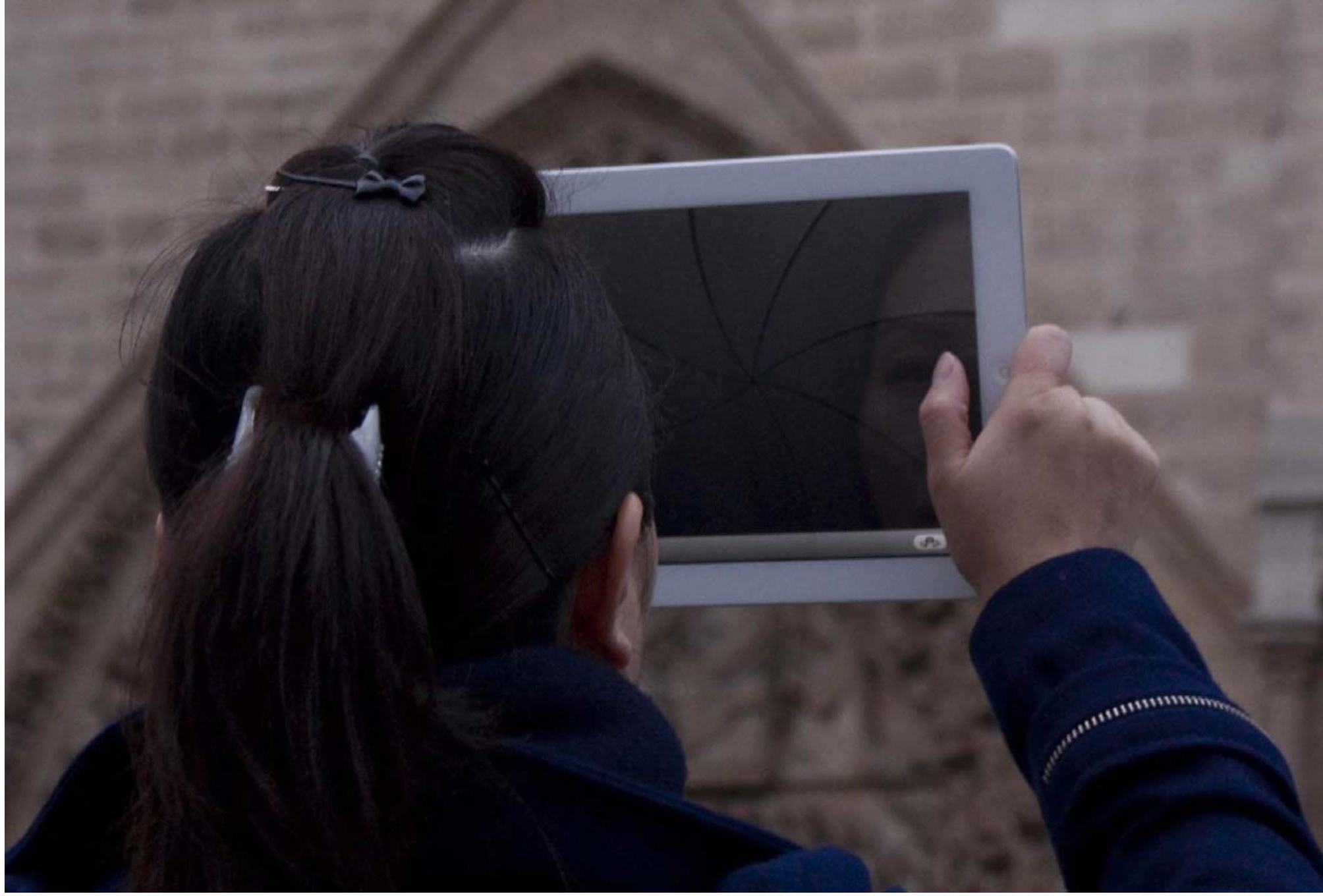



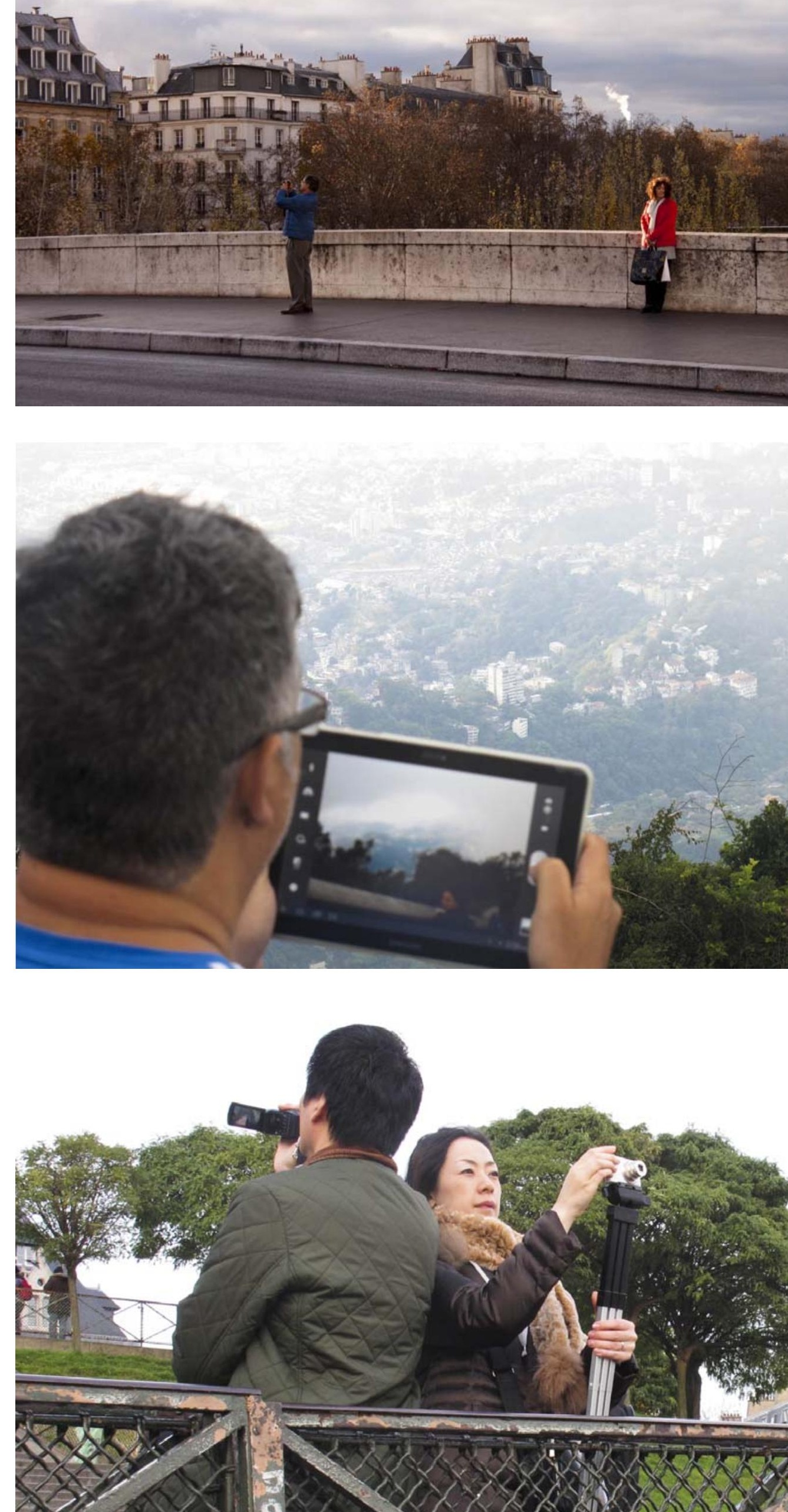


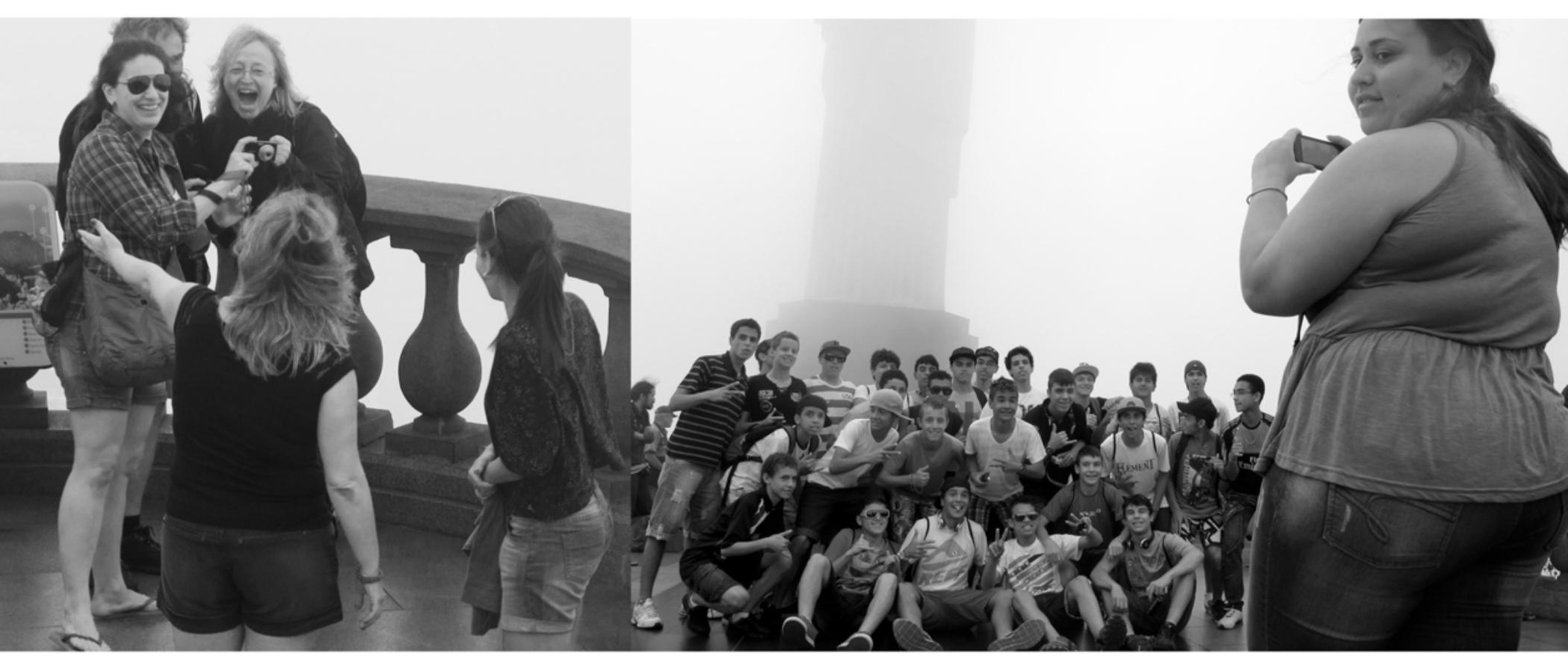




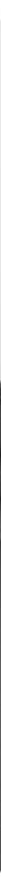




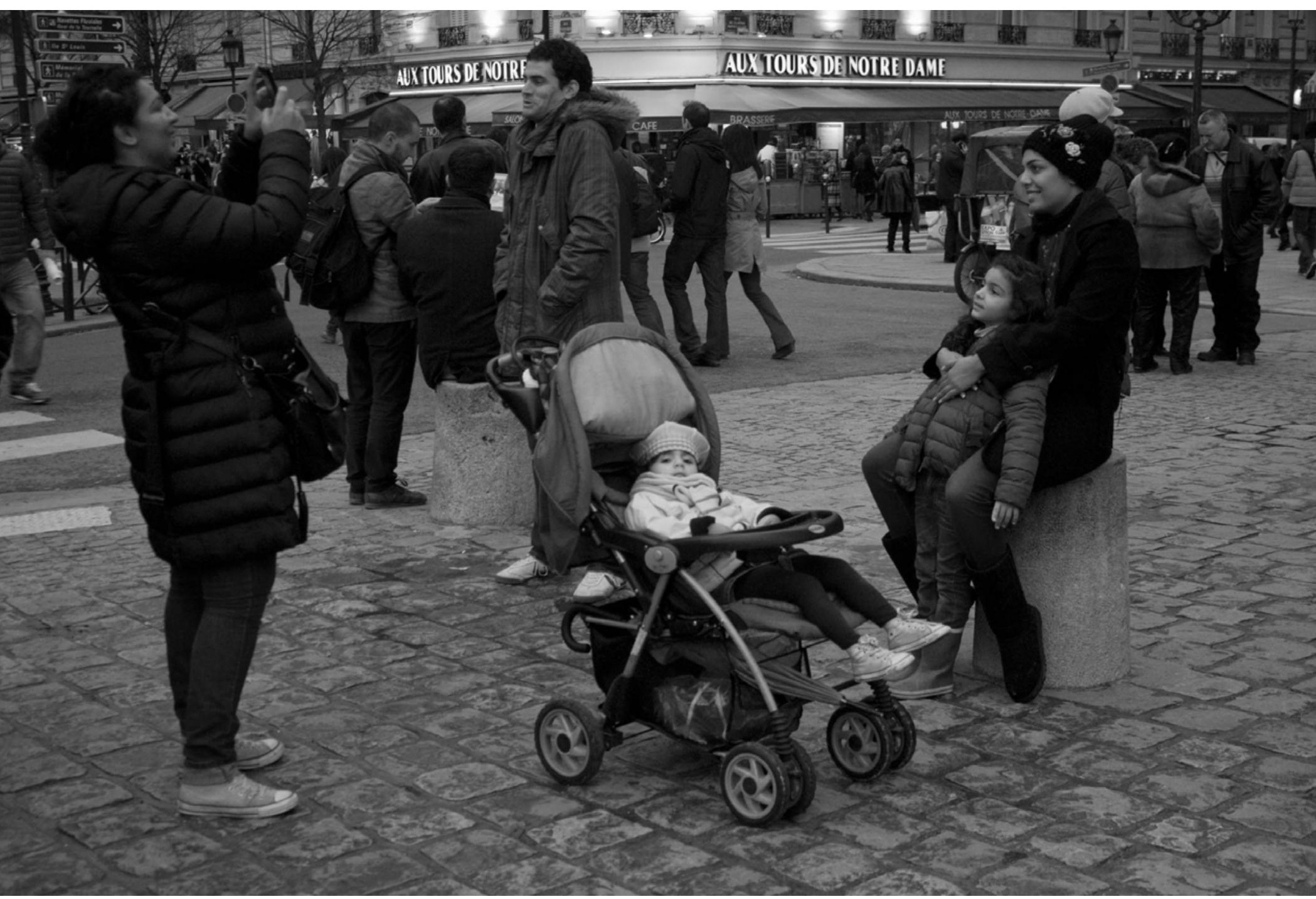




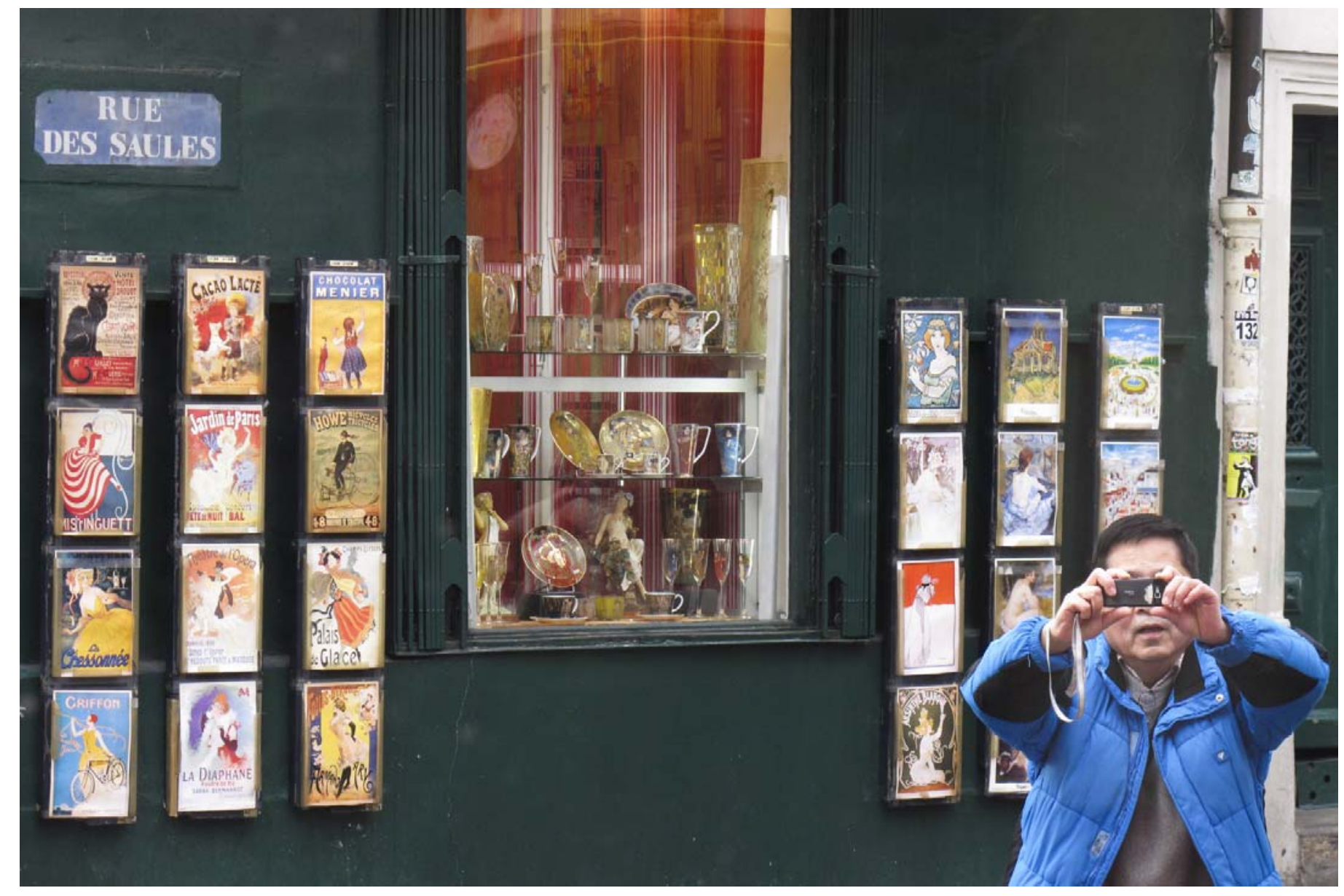

